\title{
Giant Prolactinoma Presenting with Neck Pain and Structural Compromise of the Occipital Condyles
}

\author{
Derek Yecies ${ }^{1} \quad$ Abdulrazag Ajlan ${ }^{1}$ John Ratliff ${ }^{1}$ Jennifer Ziskin ${ }^{2}$ Peter Hwang ${ }^{3}$ Hannes Vogel ${ }^{2}$ \\ Laurence Katznelson $^{1,4}$ Griffith Harsh IV ${ }^{1}$
}

${ }^{1}$ Department of Neurosurgery, Stanford University School of Medicine, Stanford, California, United States

2 Department of Pathology, Stanford University School of Medicine, Stanford, California, United States

${ }^{3}$ Department of Otolaryngology - Head \& Neck Surgery, Stanford University School of Medicine, Stanford, California, United States

${ }^{4}$ Department of Medicine, Stanford University School of Medicine, Stanford, California, United States

\begin{abstract}
Address for correspondence Abdulrazag Ajlan, MD, Department of Neurosurgery, Stanford University, 1078 Tanland Dr., Unit 103, Palo Alto, CA 94303, United States (e-mail: aajlan@stanford.edu).
\end{abstract}

J Neurol Surg Rep 2015;76:e297-e301.

\begin{abstract}
Keywords

- pituitary adenoma

- giant prolactinoma

- occipitocervical instability

- occipital condyles

- invasive adenoma

Prolactinomas are the most common form of endocrinologically active pituitary adenoma; they account for $\sim 45 \%$ of pituitary adenomas encountered in clinical practice. Giant adenomas are those $>4 \mathrm{~cm}$ in diameter. Less than $0.5 \%$ of pituitary adenomas encountered in neurosurgical practice are giant prolactinomas. Patients with giant prolactinomas typically present with highly elevated prolactin levels, endocrinologic disturbances, and neurologic symptoms from mass-induced pressure. Described here is an unusual case of a giant prolactinoma presenting with neck pain and structural compromise of the occipital condyles. Transnasal biopsy of the nasopharyngeal portion of the mass obtained tissue consistent with an atypical prolactinoma with $\mathrm{p} 53$ reactivity and a high Ki-67 index of 5\%. Despite the size and invasiveness of the tumor, the patient had resolution of his clinical symptoms, dramatic reduction of his hyperprolactinemia, and near-complete disappearance of his tumor following medical treatment.
\end{abstract}

\section{Introduction}

Pituitary adenomas are common intracranial lesions; autopsy and radiographic studies find a prevalence of $\sim 17 \%{ }^{1}$ Prolactinomas are the most common form of endocrinologically active pituitary adenoma; they account for $\sim 45 \%$ of pituitary adenomas encountered in clinical practice. ${ }^{2}$ Prolactinomas are most often microadenomas $(<10 \mathrm{~mm}$ in diameter) and are diagnosed more frequently in women, who usually present with the hormonal sequelae of hyperprolactinemia including galactorrhea and oligomenorrhea. In men, macroprolactinomas ( $>10 \mathrm{~mm}$ in diameter) are more commonly detected, and it has been hypothesized that the greater subtlety of male hormonal symptoms of hyperprolactinemia, gynecomastia, decreased libido, and impotence may account for the lower observed frequency and the larger size of clinically evident prolactinomas in men. ${ }^{3}$

Giant prolactinomas are $>4 \mathrm{~cm}$ in diameter. The true incidence is unknown; one case series reported that $0.5 \%$ of pituitary adenomas encountered in neurosurgical practice are giant prolactinomas. ${ }^{4}$ Patients with giant prolactinomas typically present with marked hyperprolactinemia ( $>1000$ $\mathrm{ng} / \mathrm{dL}$ ), hypogonadism, and neurologic symptoms from massinduced pressure on or invasion of adjacent structures. received

July 17, 2014

accepted after revision

August 28, 2015

published online

October 29, 2015
DOI http://dx.doi.org/

10.1055/s-0035-1566124. ISSN 2193-6358. (c) 2015 Georg Thieme Verlag KG
Stuttgart · New York

License terms

(1) $\circledast \circledast$ 
Described here is an unusual case of a giant prolactinoma presenting with neck pain and structural compromise of the occipital condyles.

\section{Case Report}

A 28-year-old man with no significant past medical history presented with 6 weeks of mild neck pain. The pain was worsened by cervical motion, with radiation to the occiput. The patient reported mild intermittent epistaxis and right nasal obstruction but denied headache, visual loss, diplopia, facial sensory abnormality, and endocrinological symptoms other than mildly decreased libido.

On examination, although the patient's head at rest tilted to the left because of neck pain, his neck had full range of motion. Formal neuro-ophthalmologic examination revealed neither visual field deficit nor diplopia. Facial sensation was normal. Magnetic resonance imaging (MRI) of the brain revealed a $70 \times 45 \times 45$ - $\mathrm{mm}$ mass isointense with the clivus on T1- and T2-weighted images and homogeneously enhancing with gadolinium. It involved the clivus, sella, and both occipital condyles, extended into the posterior nasopharynx, and encased the cavernous and infraclinoid segments of both internal carotid arteries ( $\mathbf{- F i g}$. 1A-F). Computed tomography showed severe bony destruction affecting both occipital condyles. An endoscopic transnasal biopsy of the nasopharyngeal portion of the mass was obtained during the first ears, nose, and throat clinic visit. Pathology revealed tissue consistent with an atypical prolactinoma with p53 reactivity and a high Ki-67 index of 5\% (- Fig. 1G-J). Endocrinologic studies were notable for prolactin $24,750 \mathrm{ng} / \mathrm{dL}$, cortisol $5.4 \mu \mathrm{g} / \mathrm{dL}$, free thyroxine $0.76 \mathrm{ng} / \mathrm{dL}$, testosterone $<20 \mathrm{ng} / \mathrm{dL}$, and insulinlike growth factor-1 of $89 \mathrm{ng} / \mathrm{mL}$.

Medical therapy of cabergoline $1 \mathrm{mg} /$ week, levothyroxine, and hydrocortisone was begun. Within 1 week, the patient's neck pain resolved. Flexion-extension plain radiographs of the cervical spine did not demonstrate instability. However, the clinical signs of occipital condyles compromise and the risk of acute occipitocervical instability and neurologic decline consequent to the near-complete replacement of both occipital condyles by tumor, and its possible exacerbation by cabergoline-induced tumor lysis, prompted an elective occiput to C2 posterior fusion (-Fig. $1 \mathbf{K}$ ).

After an uncomplicated recovery from surgery, the patient remained free of neck pain. Throughout his first year of cabergoline therapy ( $3 \mathrm{mg} /$ week), his only complaint was infrequent nasal moisture that was not believed to represent cerebrospinal fluid (CSF) rhinorrhea. One year after treatment, his prolactin had fallen to $36 \mathrm{ng} / \mathrm{dL}$, and MRI showed a dramatic reduction in tumor size (-Fig. 1L).

\section{Discussion}

This is an unusual case of a giant prolactinoma presenting with neck pain and near-complete destruction of the occipital condyles requiring occipitocervical fusion. Literature review reveals only three cases of prolactinoma invading the occipital condyles and requiring occipitocervical fusion; one patient with an unstable pathologic fracture underwent an occipitocervical fusion and 8 years later was diagnosed with a giant prolactinoma, ${ }^{5}$ one patient presented with acute neurologic deterioration due to compression of the brainstem and pons, ${ }^{6}$ and one had invasion of the occipital condyles and subsequent occipitocervical instability as a late sequela of a prolactinoma initially treated with radiation. ${ }^{7}$ However, this case represents the first report of a patient with a pituitary adenoma initially presenting with symptoms solely attributable to the invasion of the occipital condyles causing neck pain.

Invasive clival masses can pose a diagnostic challenge. Considerations include pituitary adenoma, atypical meningioma, chordoma, chondrosarcoma, osteosarcoma, plasmacytoma, sinonasal malignancy, mucocele of the sphenoid sinus, intraosseous lymphoma, neuroenteric cyst, craniopharyngioma, and metastasis. It is not always possible to differentiate chordoma from pituitary adenoma. Both are typically contrast enhancing. When assessed with MRI, chordomas are typically very $\mathrm{T} 2$ hyperintense, whereas pituitary adenomas are typically T2 isointense; however, macroadenomas may have heterogeneous $\mathrm{T} 2$ signal. $^{8-10}$ In this case, the lesion was largely T2 isointense with some heterogeneous T2 signal that is consistent with the pathologic diagnosis of pituitary adenoma. Many pituitary adenomas that invade the clivus are initially misdiagnosed as chordomas. ${ }^{11-14}$ This case highlights the importance of maintaining a broad differential diagnosis for clival masses and particularly including pituitary adenoma for lesions involving the sella turcica that are T2 isointense.

Based on the 2004 World Health Organization (WHO) classification of pituitary adenomas, this tumor met the criteria for an atypical adenoma. ${ }^{15}$ These tumors are distinguished by a Ki-67 proliferative index $>3 \%$, excessive p53 immunoreactivity, and increased mitotic activity, and such atypical adenomas are described as intermediate between benign pituitary adenomas and pituitary carcinomas. ${ }^{15}$ The incidence of atypical pituitary adenomas in surgical series ranged from $2.7 \%$ in the German Pituitary Tumor Registry ${ }^{16}$ to $15 \%$ in the series of Zada et al. ${ }^{17}$ Prolactinomas represented $8 \%$ and $11 \%$ of atypical adenomas in these two series, respectively. The classification of atypical pituitary adenomas has engendered significant controversy. Notably, the WHO classification does not include invasiveness as a criterion for designation as atypical. The implications of immunohistochemical findings are also controversial; conflicting reports support $^{18-20}$ and discount ${ }^{21-23}$ the value of Ki-67 proliferative indexes and p53 immunoreactivity in predicting the behavior of pituitary adenomas. In the largest case series of atypical pituitary adenomas published to date, Zada et al found atypical adenomas were significantly more likely to be invasive on MRI imaging than are typical adenomas. ${ }^{17}$ The atypical tumor in our case was highly invasive.

Neither our case nor those of Zada et al had the long-term follow-up required to link atypical histology and invasiveness with risk of recurrence. But a study of 410 patients who underwent resection of a pituitary adenoma, including 116 patients who underwent resection of a prolactinoma, 

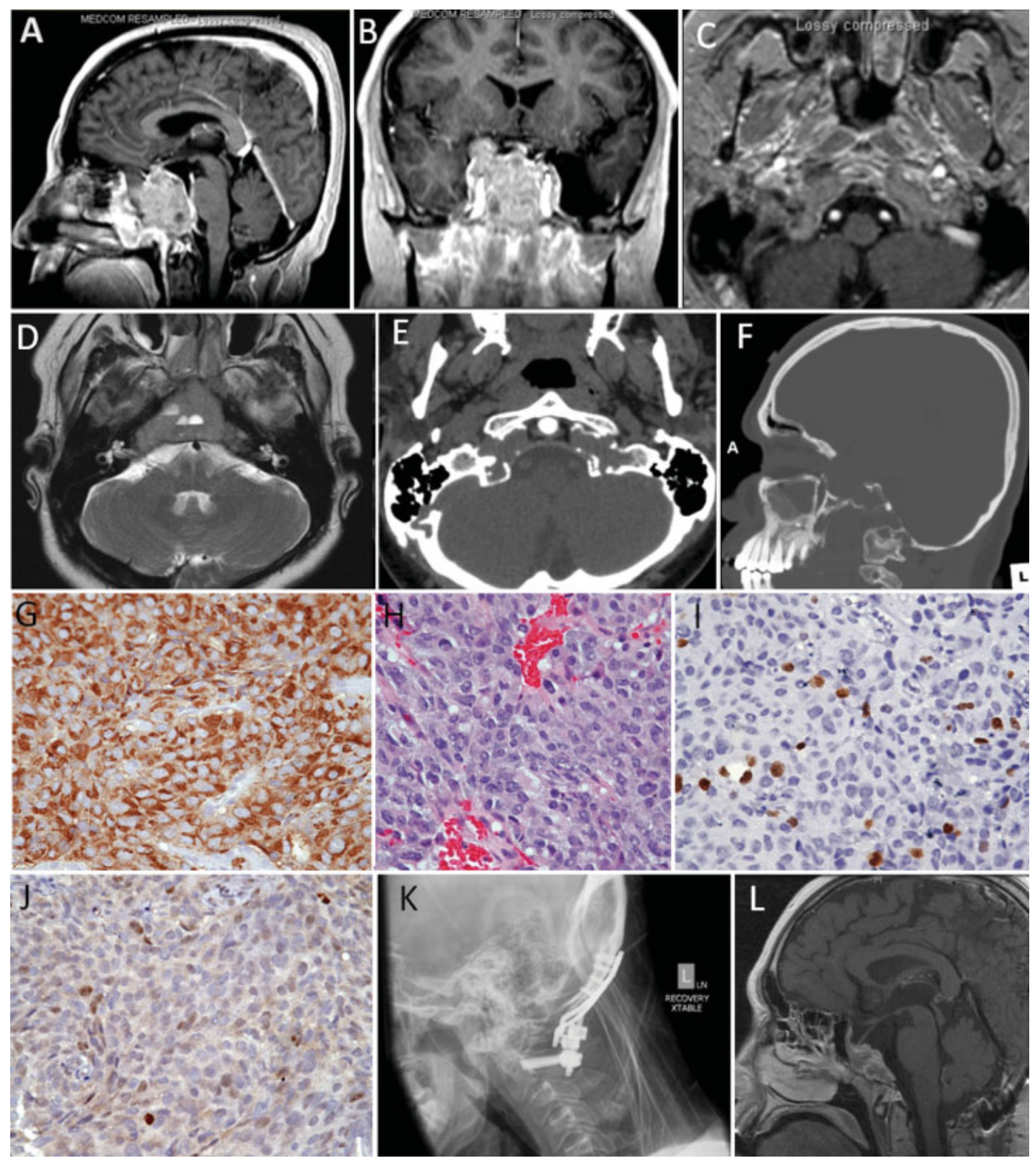

Fig. 1 (A-C) T1-weighted postcontrast magnetic resonance imaging (MRI) scan displays a large contrast-enhancing mass. (D) T-2 weighted noncontrast MRI scan shows a large isointense mass with areas of heterogeneous and hyperintense signal. (E, F) Axial and sagittal noncontrast computed tomography CT scans show destruction of both occipital condyles. (G) Hematoxylin and eosin, prolactin, (I) Ki-67, and (J) p53 stained slides of biopsy tissue from the intranasal portion of the tumor display morphology and staining consistent with an atypical prolactinoma. (K) Postoperative lateral X-ray shows posterior occipit-C2 instrumented fusion. (L) Sagittal T1-weighted postcontrast MRI scan following 1 year of cabergoline therapy demonstrates significant reduction in tumor volume.

suggests that tumors that are invasive and "proliferative" (assessed by Ki-67 positivity, mitoses per high-powered field, and p53 positivity) had 25 - and 12 -fold rates of residual tumor and tumor progression after 8 years of postoperative follow-up when compared with noninvasive, nonproliferative adenomas. ${ }^{24}$ However, neither of these studies specifically addressed giant prolactinomas treated nonoperatively.

Despite the large size and invasive nature of this patient's prolactinoma, dramatic reductions of tumor size and prolac- tin level were achieved with medical therapy alone. This is consistent with prior reports in the literature regarding the sensitivity of giant prolactinomas to dopamine agonists. ${ }^{4,25-29}$ Recent case series of surgical treatment of giant adenomas report rates of gross total resection of only 14 to $61 \%$, of significant complications of up to $18 \%,{ }^{30-34}$ and of mortality of 0 to $4.6 \%$. In contrast, medical therapy has significantly lower complication rates and no mortality. Nonetheless, treatment of giant prolactinomas with 
dopamine agonists is not without potential complications including CSF fistula, ${ }^{35,36}$ pneumocephalus, ${ }^{37}$ pituitary apoplexy, ${ }^{38}$ optic chiasm herniation, ${ }^{39}$ and brainstem angulation. ${ }^{40}$ However, given the high efficacy and low relative morbidity of dopamine antagonism, medical therapy should remain the first-line treatment for giant prolactinomas.

\section{Conclusion}

This is the first reported case of a giant prolactinoma presenting with neck pain secondary to invasion of the occipital condyles and only the fourth reported case of a prolactinoma causing structural compromise of the occipital condyles requiring occipitocervical fusion. Pituitary adenoma should be included in the initial differential diagnosis of all lesions in or about the sella. Despite the size and invasiveness of the tumor, the patient had resolution of his clinical symptoms, dramatic reduction of his hyperprolactinemia, and near-complete disappearance of his tumor following medical treatment with a dopamine agonist.

\section{References}

1 Ezzat S, Asa SL, Couldwell WT, et al. The prevalence of pituitary adenomas: a systematic review. Cancer 2004;101(3): 613-619

2 Ciccarelli A, Daly AF, Beckers A. The epidemiology of prolactinomas. Pituitary 2005;8(1):3-6

3 Pinzone JJ, Katznelson L, Danila DC, Pauler DK, Miller CS, Klibanski A. Primary medical therapy of micro- and macroprolactinomas in men. J Clin Endocrinol Metab 2000;85(9): 3053-3057

4 Shrivastava RK, Arginteanu MS, King WA, Post KD. Giant prolactinomas: clinical management and long-term follow up. J Neurosurg 2002;97(2):299-306

5 Murphy FY, Vesely DL, Jordan RM, Flanigan S, Kohler PO. Giant invasive prolactinomas. Am J Med 1987;83(5):995-1002

6 Zaben MJ, Harrisson SE, Mathad NV. Giant prolactinoma causing cranio-cervical junction instability: a case report. Br J Neurosurg 2011;25(6):754-756

7 Laws ER Jr, Ivins JC. Atlanto-occipital instability as a result of pituitary adenoma: case report with successful management by cervico-occipital fusion. Johns Hopkins Med J 1979;145(3): 136-138

8 Chaudhary V, Bano S. Imaging of the pituitary: recent advances. Indian J Endocrinol Metab 2011;15(Suppl 3):S216-S223

9 Yeom KW, Lober RM, Mobley BC, et al. Diffusion-weighted MRI: distinction of skull base chordoma from chondrosarcoma. AJNR Am J Neuroradiol 2013;34(5):1056-1061; S1

10 Pisaneschi M, Kapoor G. Imaging the sella and parasellar region. Neuroimaging Clin N Am 2005;15(1):203-219

11 Wong K, Raisanen J, Taylor SL, McDermott MW, Wilson CB, Gutin PH. Pituitary adenoma as an unsuspected clival tumor. Am J Surg Pathol 1995;19(8):900-903

12 Ballaux D, Verhelst J, Pickut B, De Deyn PP, Mahler C. Ectopic macroprolactinoma mimicking a chordoma: a case report. Endocr Relat Cancer 1999;6(1):117-122

13 Rocque BG, Herold KA, Salamat MS, Shenker Y, Kuo JS. Symptomatic hyperprolactinemia from an ectopic pituitary adenoma located in the clivus. Endocr Pract 2009;15(2):143-148

14 Wan Y, Xie D, Yang S, et al. Acromegaly with an ectopic clival pituitary adenoma: case report and review of literature. Neurosurg Q 2015;25(1):105-107
15 DeLellis R, Loyd R, Hetiz P, Eng C, eds. World Health Organization Classification of Tumours: Tumours of Endocrine Organs. Lyon, France: IARC Press; 2004

16 Saeger W, Lüdecke DK, Buchfelder M, Fahlbusch R, Quabbe HJ, Petersenn S. Pathohistological classification of pituitary tumors: 10 years of experience with the German Pituitary Tumor Registry. Eur J Endocrinol 2007;156(2):203-216

17 Zada G, Woodmansee WW, Ramkissoon S, Amadio J, Nose V, Laws ER Jr. Atypical pituitary adenomas: incidence, clinical characteristics, and implications. J Neurosurg 2011;114(2): 336-344

18 Thapar K, Kovacs K, Scheithauer BW, et al. Proliferative activity and invasiveness among pituitary adenomas and carcinomas: an analysis using the MIB-1 antibody. Neurosurgery 1996;38(1): 99-106; discussion 106-107

19 Thapar K, Scheithauer BW, Kovacs K, Pernicone PJ, Laws ER Jr. p53 expression in pituitary adenomas and carcinomas: correlation with invasiveness and tumor growth fractions. Neurosurgery 1996;38(4):765-770; discussion 770-771

20 Tanaka Y, Hongo K, Tada T, Sakai K, Kakizawa Y, Kobayashi S. Growth pattern and rate in residual nonfunctioning pituitary adenomas: correlations among tumor volume doubling time, patient age, and MIB-1 index. J Neurosurg 2003;98(2): 359-365

21 Ma W, Ikeda H, Yoshimoto T. Clinicopathologic study of 123 cases of prolactin-secreting pituitary adenomas with special reference to multihormone production and clonality of the adenomas. Cancer 2002;95(2):258-266

22 Oliveira MC, Marroni CP, Pizarro CB, Pereira-Lima JF, BarbosaCoutinho LM, Ferreira NP. Expression of p53 protein in pituitary adenomas. Braz J Med Biol Res 2002;35(5):561-565

23 Gejman R, Swearingen B, Hedley-Whyte ET. Role of Ki-67 proliferation index and p53 expression in predicting progression of pituitary adenomas. Hum Pathol 2008;39(5):758-766

24 Trouillas J, Roy P, Sturm N, et al; members of HYPOPRONOS. A new prognostic clinicopathological classification of pituitary adenomas: a multicentric case-control study of 410 patients with 8 years post-operative follow-up. Acta Neuropathol 2013;126(1): 123-135

25 Shimon I, Benbassat C, Hadani M. Effectiveness of long-term cabergoline treatment for giant prolactinoma: study of 12 men. Eur J Endocrinol 2007;156(2):225-231

26 Corsello SM, Ubertini G, Altomare M, et al. Giant prolactinomas in men: efficacy of cabergoline treatment. Clin Endocrinol (Oxf) 2003;58(5):662-670

27 Acharya SV, Gopal RA, Menon PS, Bandgar TR, Shah NS. Giant prolactinoma and effectiveness of medical management. Endocr Pract 2010;16(1):42-46

28 Cho EH, Lee SA, Chung JY, et al. Efficacy and safety of cabergoline as first line treatment for invasive giant prolactinoma. J Korean Med Sci 2009;24(5):874-878

29 Rahmanian M, Meybodi HA, Larijani B, Mohajeri-Tehrani MR. Giant prolactinoma: case report and review of literature. J Diabetes Metab Disord 2013;12(1):3

30 Zhao B, Wei YK, Li GL, et al. Extended transsphenoidal approach for pituitary adenomas invading the anterior cranial base, cavernous sinus, and clivus: a single-center experience with 126 consecutive cases. J Neurosurg 2010;112(1):108-117

31 Sinha S, Sharma BS. Giant pituitary adenomas-an enigma revisited. Microsurgical treatment strategies and outcome in a series of 250 patients. Br J Neurosurg 2010;24(1):31-39

32 Garibi J, Pomposo I, Villar G, Gaztambide S. Giant pituitary adenomas: clinical characteristics and surgical results. Br J Neurosurg 2002;16(2):133-139

33 Goel A, Nadkarni T, Muzumdar D, Desai K, Phalke U, Sharma P. Giant pituitary tumors: a study based on surgical treatment of 118 cases. Surg Neurol 2004;61(5):436-445; discussion 445446 
34 Mortini P, Barzaghi R, Losa M, Boari N, Giovanelli M. Surgical treatment of giant pituitary adenomas: strategies and results in a series of 95 consecutive patients. Neurosurgery 2007;60(6): 993-1002; discussion 1003-1004

35 Leong KS, Foy PM, Swift AC, Atkin SL, Hadden DR, MacFarlane IA. CSF rhinorrhoea following treatment with dopamine agonists for massive invasive prolactinomas. Clin Endocrinol (Oxf) 2000; 52(1):43-49

36 Suliman SG, Gurlek A, Byrne JV, et al. Nonsurgical cerebrospinal fluid rhinorrhea in invasive macroprolactinoma: incidence, radiological, and clinicopathological features. J Clin Endocrinol Metab 2007;92(10):3829-3835
37 Machicado JD, Varghese JM, Orlander PR. Cabergoline-induced pneumocephalus in a medically treated macroprolactinoma. J Clin Endocrinol Metab 2012;97(10):3412-3413

38 Knoepfelmacher M, Gomes MC, Melo ME, Mendonca BB. Pituitary apoplexy during therapy with cabergoline in an adolescent male with prolactin-secreting macroadenoma. Pituitary 2004;7(2):83-87

39 Jones SE, James RA, Hall K, Kendall-Taylor P. Optic chiasmal herniation -an under recognized complication of dopamine agonist therapy for macroprolactinoma. Clin Endocrinol (Oxf) 2000;53(4):529-534

40 Lou XH, Wu ZB, Zhang YZ. Bromocriptine-induced brainstem angulation in a patient with invasive prolactinoma. J Clin Endocrinol Metab 2013;98(3):867-868 